\title{
Hypertension and periodontal status in Senegalese patients: A case-control study
}

\author{
Mohamed Leye ${ }^{1,2}$, Massamba Diouf ${ }^{3}$, William Stéve Térence Madozein ${ }^{3}$, Modou Jobe ${ }^{4}$, \\ El Hadj Mbacke Sarr ${ }^{1}$, Simon Joel Manga ${ }^{1}$, Arame Diagne Diallo ${ }^{1}$, Ibrahima Bara Diop ${ }^{1}$
}

${ }^{1}$ Cardiology Department, Fann University Hospital, Dakar, Senegal

${ }^{2}$ Unit of Training and Research in Health Sciences, Thiès University, Thiès, Senegal

${ }^{3}$ Public Health Office, Dentistry School, Cheikh Anta Diop University, Dakar, Senegal

${ }^{4}$ Cardiology Department, Aristide Le Dantec University Hospital, Dakar, Senegal

Email: dioufmass78@yahoo.fr

Received 2 December 2013; revised 2 January 2014; accepted 10 January 2014

Copyright (C) 2014 Mohamed Leye et al. This is an open access article distributed under the Creative Commons Attribution License, which permits unrestricted use, distribution, and reproduction in any medium, provided the original work is properly cited. In accordance of the Creative Commons Attribution License all Copyrights (C) 2014 are reserved for SCIRP and the owner of the intellectual property Mohamed Leye et al. All Copyright (C) 2014 are guarded by law and by SCIRP as a guardian.

\section{ABSTRACT}

Introduction: Hypertension is a public health concern worldwide due to its known consequences. The literature has shown a close relationship between periodontal disease and systemic diseases, especially hypertension. The objective of this study was to determine the periodontal risk factors involved in the occurrence or severity of hypertension in a population of patients attending the cardiology department of Fann University Hospital located in an urban Dakar region. Methodology: This was a case-control study involving 246 patients of whom 123 were hypertensive patients (cases) and 123 non-hypertensive patients (controls). The data collected include sociodemographic characteristics, lifestyle, risk factors, and data on hypertension and on periodontal disease: plaque index, papillary bleeding index, clinical attachment loss, pocket depth and community periodontal index and treatment needs (CPITN). Data in univariate analysis were expressed as proportions and averages and odd ratios with their confidence intervals. Results: The average age in the cases group was $58 \pm 11.4$ years and $34.5 \pm 14.2$ years in the control group. The body mass index (BMI) averaged 27.1 $\pm 6 \mathrm{~kg} / \mathrm{m}^{2}$ and $23.2 \pm 4.6 \mathrm{~kg} / \mathrm{m}^{2}$ respectively in cases and controls. Hypertensive patients had on average more severe periodontal characteristics than non-hypertensives (PAC of $2.8 \pm 1859$ versus $0.8 \pm 1.325$ ) (CPITN $2.5 \pm 0.998$ versus $1.2 \pm 1.074$ ) and the risk of developing hypertension adjusted for age, physical inactivity, heredity and other parameters was twice more when the patient had periodontitis. Conclusion: It is necessary to have a more integrated approach in the management of hypertension, which should take into account oro-dental factors.

\section{KEYWORDS}

Hypertension; Periodontal Disease; Senegal

\section{INTRODUCTION}

According to the World Health Organization (WHO), cardiovascular diseases are the leading cause of death in the world followed by infectious diseases, parasitic diseases and cancers. Estimated 17.5 million deaths in 2005 were attributed to cardiovascular diseases. These diseases incriminate hypertension which were closely associated with endothelial dysfunction thereby promoting the atherosclerotic process, as a major risk factor [1,2]. Over $80 \%$ of deaths related to these diseases occur in low and middle income countries and affect all people regardless of age and sex [3]. Several risk factors such as smoking, diabetes, hypertension, obesity, dyslipidemia and physical inactivity, are described as being associated with the onset or worsening of cardiovascular diseases $[4,5]$. These same factors are also involved in the development and severity of periodontal disease [6,7]. These inflammatory diseases are essentially of polymicrobial origin with the formation of periodontal pockets most often of a bacterial reservoir. There may be bacteremia resulting from these infected sites [8].

Periodontal disease, caused by periodontal pathogens is a chronic inflammatory disease of the dental supporting structures. Its occurrence which is modulated by both hosts' genetic and acquired factors is associated with systemic inflammation. The common risk factor ap- 
proach and the intermediary role played by the periodontium between the teeth and the rest of the body because of its extensive gingival, periodontal ligament and alveolar vascularization might elucidate its involvement in the development or worsening of hypertension $[3,7,8]$.

Many studies have demonstrated an association between periodontal state and cardiovascular disease, especially hypertension. Leite [9], in an experimental study on laboratory rats in Brazil in 2005 concluded that hypertension has a significant impact on worsening periodontal pocket depth. A cross-sectional study by Angeli et al. in 2003 in Italy on the correlation between left ventricular mass and severity of periodontitis on 104 patients reported a direct association between these two parameters [4].

In Africa, very few studies have examined the relationship between periodontal disease and hypertension. Because of this, in the context of exploring the relationship between heart disease and oral health, we focus on hypertension. The objective of this study was to determine the periodontal risk factors involved in the occurrence or the severity of hypertension in a population of patients attending the cardiology department of Fann University Hospital in Dakar.

\section{METHODS}

The department of cardiology of Fann University Hospital where this study was carried out receives patients from all social classes presenting with different cardiovascular problems. This was a case control, hospital-based study carried out in an urban Dakar region, Senegal. A signed informed consent was obtained from all the participants.

\subsection{Study Population}

Cases comprised patients with a known history of hypertension whilst the controls were recruited from the patients referred to the department of cardiology of Fann University Hospital but who have been found to be free from cardiovascular disease.

\subsubsection{Definition of Cases}

Patients with a documented systolic blood pressure (SBP) $\geq 140 \mathrm{mmHg}$ and/or diastolic blood pressure (DBP) $\geq$ $90 \mathrm{mmHg}$ measured in a sitting or lying position, after 10 minutes of rest in at least 2 different consultations.

\subsubsection{Definition of Controls}

Patients with normal blood pressure values (SBP $<140$ $\mathrm{mmHg}$ and DBP $<90 \mathrm{mmHg}$ ) and not taking antihypertensive medication were considered as controls.

\subsubsection{Exclusion Criteria}

Patients with diagnosed acquired or congenital heart disease, patients undergoing immunosuppressive treatment; patients whose health did not allow for a clinical periodontal examination, patients who received periodontal treatment during the last six months, patients who have lost more than $75 \%$ of their teeth were excluded from the study.

The cases and controls were recruited consecutively according to their order of presentation.

\subsection{Matching}

The matching was done according to patients' gender in such a way that if the case was male, the control was and vice versa such that at the end of the survey the number of cases was equal to the number of controls (Ratio $=1$ ).

\subsubsection{Sample Size}

The sample size was calculated using Epi-info version 5.3.1. Considering a risk of $5 \%$ with a power of $80 \%$ with reference to the study by Diallo et al. [7], we made a theoretical exposure to periodontal disease of $32 \%$ in controls. The risk of having hypertension when the patient had periodontitis was determined. Thus, the sample size was 123 cases and 123 controls.

\subsubsection{Data Collection Procedure and Variables Studied}

Data were collected using a specially designed questionnaire which was pre-tested in 10 patients attending the cardiology clinic at Fann university hospital. This enabled us to observe the reaction of participants to the survey and to obtain estimates of time spent in various sections. It took place during the working hours of all days from April to June 2011 and involved all patients who met the inclusion criteria.

The data collected include socio-demographic characteristics: age, gender, ethnicity, occupation, weight, height, address; lifestyle: consumption of tobacco, alcohol, coffee, cola and others; other known risk factors: diabetes, obesity, heredity, sedentarism. Data on hypertension and cardiovascular risk factors: history of hereditary coronary heart disease (myocardial infarction before age 55 years in a first-degree relative of both sexes, early stroke before the age of 45), family history of hypertension, signs of Dieulafoy, systolic blood pressure, diastolic blood pressure.

The periodontal features collected include: plaque index, gingival index, pocket depth, clinical attachment loss, community periodontal index and treatment needs (CPITN) collected according to the recommendations of Bercy and Martin [10].

\subsubsection{Exposition}

It involved independent variables: socio-demographic variables, medical history and the primary independent variable was periodontitis. Periodontitis was defined as clinical attachment loss of $\geq 3 \mathrm{~mm}$ and a pocket depth of $\geq 4 \mathrm{~mm}$. 
A fully equipped tray with a graduated periodontal probe was used to perform periodontal measures. The measurements were made by a student doing thesis at the department of dental surgery who was previously trained for these types of evaluations.

\subsubsection{Measure of Outcome}

The measured outcome, hypertension, was made with an aneroid sphygmomanometer (Spengler) by auscultatory method. These measures were taken by a cardiologist who after the clinical examination referred the patient to the dental surgery student for dental additional data.

\subsection{Data Analysis}

Data was entered into Epi info version 5.3.1. Univariate analysis made with the same software was essentially descriptive, mainly proportions and averages of the variables studied. Some variables were redefined, dichotomized by grouping terms as either yes or no.

The associations between qualitative variables were studied; their strengths were determined by odd ratios with confidence intervals. Modelling with backward selection was developed with variables whose $\mathrm{p}$ was less than 0.25 in univariate analysis. At each step, the variable associated with the largest p-value was eliminated from the model at $5 \%$. The procedure was stopped when all variables remaining in the model had p-value less than the threshold with the exception of those forced. To monitor the model-building, we checked each output variable, the change in odd ratio of the primary independent variable "periodontitis" by calculating the relative fluctuation. Interactions with the variable "periodontitis" were tested. R software version 2.9.0 was used. The results were marginally significant for $\mathrm{p}=5 \%$ and significant when $\mathrm{P}$ was less than $5 \%$.

\section{RESULTS}

Table 1 shows the socio-demographic characteristics, lifestyle and medical history of 123 hypertensive patients (cases) and 123 non-hypertensive patients (controls).

On socio-demographics, the average age of cases was $58 \pm 11.4$ years and $34.5 \pm 14.2$ years in controls. The body mass index (BMI) averaged $27.1 \pm 6 \mathrm{~kg} / \mathrm{m}^{2}$ in cases and $23.2 \pm 4.6 \mathrm{~kg} / \mathrm{m}^{2}$ in controls. There were also more retired people among cases (79.7\%) than in controls (43.1\%) compared to other occupational groups namely the employed $(15.4 \%$ in cases compared $27.6 \%$ in controls) and students who are more among controls $29.3 \%$.

Regarding lifestyle, very few patients in our study smoked whether actively (4.9\%) or passively $(2.4 \%$ in cases against $3.3 \%$ in controls), and also very few consumed alcohol (3.3\% of cases and $7.3 \%$ of controls). On the other hand, $69.1 \%$ of cases versus $19.5 \%$ were sedentary, $64.2 \%$ of cases versus $75.6 \%$ of controls take
Table 1. Comparative characteristics of cases and controls.

\begin{tabular}{|c|c|c|c|}
\hline \multicolumn{3}{|c|}{ Socio-demographic characteristics } & \multirow{2}{*}{$\begin{array}{c}\text { p-value } \\
\text { (TTEST or TEST KHI2 } \\
\text { or Fischer TEST) }\end{array}$} \\
\hline Variables & $\begin{array}{c}\text { Cases } \\
\text { (N = 123) }\end{array}$ & $\begin{array}{l}\text { controls } \\
(\mathrm{N}=123)\end{array}$ & \\
\hline Age in years (SD) & $58.0(11.4)$ & $34.5(14.2)$ & $\mathrm{p}<0.001$ \\
\hline $\mathrm{BMI} \mathrm{kg} / \mathrm{m}^{2}$ (SD) & $27.1(6.0)$ & $23.2(4.6)$ & $\mathrm{p}<0.001$ \\
\hline $\begin{array}{l}\text { Occupation } \\
\text { Students (\%) }\end{array}$ & 0.8 & 29.3 & $\mathrm{p}<0.001$ \\
\hline Employed (\%) & 15.4 & 27.6 & \\
\hline Retired (\%) & 79.7 & 43.1 & \\
\hline Others (\%) & 4.1 & 0 & \\
\hline \multicolumn{4}{|c|}{ Characteristics related to lifestyle } \\
\hline Variables & $\begin{array}{c}\text { Cases } \\
(\mathrm{N}=123)\end{array}$ & $\begin{array}{l}\text { Controls } \\
(\mathrm{N}=123)\end{array}$ & \\
\hline Active smokers (\%) & 4.9 & 4.9 & 1.000 \\
\hline Passive smokers (\%) & 2.4 & 3.3 & 1.000 \\
\hline Coffee (\%) & 64.2 & 75.6 & 0.052 \\
\hline Cola nuts (\%) & 22.8 & 17.1 & 0.264 \\
\hline Alcohol (\%) & 3.3 & 7.3 & 0.254 \\
\hline Sedentarism (\%) & 69.1 & 19.5 & $\mathrm{p}<0.001$ \\
\hline \multicolumn{4}{|c|}{ Past medical history } \\
\hline Variables & $\begin{array}{c}\text { Cases } \\
(\mathrm{N}=123)\end{array}$ & $\begin{array}{l}\text { Controls } \\
(\mathrm{N}=123)\end{array}$ & \\
\hline Diabetes (\%) & 21.1 & 5.7 & $\mathrm{p}<0.001$ \\
\hline Heredity (\%) & 52 & 39 & 0.041 \\
\hline Obesity (\%) & 30.9 & 7.3 & $\mathrm{p}<0.001$ \\
\hline
\end{tabular}

coffee. $22.8 \%$ of cases and $17.1 \%$ of controls consumed cola nuts.

Past medical history showed respectively the presence of diabetes, heredity and obesity in $21.1 \%, 52 \%$ and $30.9 \%$ of cases. There were fewer controls with diabetes (5.7\%), obesity (7.3\%), and family history of hypertension (39\%).

All periodontal characteristics were significantly associated with hypertension in univariate analysis.

Table 3 presents the final model retained after multivariate analysis using the down manual procedure. It appears that periodontitis was significantly associated with hypertension ( $\mathrm{P}=0.001$ ) after adjustment for physical inactivity, heredity, age, age-periodontitis interaction and other periodontal parameters. 


\section{DISCUSSION}

This study shows that there is an association between periodontal state and hypertension in Senegalese patients. The risk of having hypertension is twice more when the patient has periodontal disease adjusted for inactivity, heredity, age, age-periodontitis interaction and other periodontal parameters.

The periodontal status of patients was assessed by indices. These indices were developed for the purpose of expressing quantitatively the value of a clinical parameter.

The oral hygiene was assessed by plaque index to determine the amount of soft deposits on tooth surfaces. The efficacy of plaque control was lower especially in cases with a score of $1.9 \pm 0.590$ (Table 1 ). By a qualitative interpretation of this index, it was found that oral hygiene was poor in patients with hypertension [10]. This lack of hygiene was probably due to poor brushing technique. In our study, the plaque index was significantly associated with hypertension $(p<0.001)$ solely after simple logistic regression (Table 2).

Inflammation as well as gingival bleeding were mild in controls $(0.7 \pm 0.669)$ and more severe in cases $(1.5 \pm$ 0.485 ) (Table 1 ) and the association remained statistically significant $(p=0.001)$ even after adjustment for age, heredity, inactivity and other periodontal parameters (Table 3). A nationwide survey carried out by Tsakos et al. in the United States showed that gingival bleeding was consistently associated with hypertension in adults ( $p<0.05)$, irrespective of the effect of socio-demographic factors, behavioral factors , physiological markers of inflammation and chronic disease [11].

While bleeding gums is a marker of active inflammation in the mouth, other measures of periodontal disease such as clinical attachment loss or pocket depth are revealing. In our study, we found a highly significant relationship between periodontitis and hypertension after adjustment for age, physical inactivity, heredity and other periodontal parameters (Table 3). Periodontal disease

Table 2. Periodontal characteristics in cases and controls.

\begin{tabular}{cccc}
\hline \multicolumn{2}{c}{ Periodontal characteristics in cases and in controls } & \multirow{2}{*}{ p-value } \\
\cline { 1 - 3 } Variables & $\begin{array}{c}\text { Cases } \\
\mathbf{( N ~ = ~ 1 2 3 ) ~}\end{array}$ & $\begin{array}{c}\text { Controls } \\
\mathbf{( N = 1 2 3 )}\end{array}$ & \\
\hline Plaque index (SD) & $1.9(0.590)$ & $1.1(0.809)$ & $\mathrm{p}<0.001$ \\
Bleeding index (SD) & $1.5(0.485)$ & $0.7(0.669)$ & $\mathrm{p}<0.001$ \\
clinical attachment loss (SD) & $2.8(1.859)$ & $0.8(1.325)$ & $\mathrm{p}<0.001$ \\
Pocket depth (SD) & $2.1(0.227)$ & $2.0(0.036)$ & $\mathrm{p}<0.001$ \\
CPITN (SD) & $2.5(0.998)$ & $1.2(1.074)$ & $\mathrm{p}<0.001$ \\
Periodontitis (\%) & 5.7 & 0 & 0.014 \\
\hline
\end{tabular}

Table 3. Periodontal factors associated with hypertension after adjustment.

\begin{tabular}{ccccc}
\hline Variables & & OR & $95 \%$ CI & p-value \\
\hline Periodontitis & Yes & 2.045 & {$[1.188-2.128]$} & 0.001 \\
& No & 1 & & \\
Age & & 1.122 & {$[1.004-1.566]$} & $\mathrm{p}<0.001$ \\
Age-Periodontitis & & 3.201 & {$[1.054-5.111]$} & 0.014 \\
Sedentarism & Yes & 2.584 & {$[1.103-6.052]$} & 0.029 \\
& No & 1 & & \\
Heredity & Yes & 7.170 & {$[2.764-18.601]$} & $\mathrm{p}<0.001$ \\
& No & 1 & & \\
Attachment Loss & & 1.241 & {$[1.008-2.324]$} & 0.025 \\
Bleeding index & & 3.494 & {$[1.675-7.291]$} & 0.001 \\
Pocket depth & & 2.118 & {$[1.555-3.700]$} & $\mathrm{p}<0.001$ \\
\hline
\end{tabular}

was defined as a clinical attachment loss $\geq 3 \mathrm{~mm}$ in at least two sites and a pocket depth $\geq 4 \mathrm{~mm}$. A previous study by Holmlund et al. in Sweden a large population showed an association between pocket depth, clinical attachment loss and hypertension [12]. According to Engstrom, hypertension was also significantly associated with periodontal pocket values greater than or equal to 5 $\mathrm{mm}$ after adjustment for age, sex, smoking and the number of remaining teeth (OR $=1.76$ and [1.14 - 2.72]) [13]. For his part, Angeli used CPITN as an endpoint of periodontal disease to investigate the relationship between CPITN and left ventricular mass in patients with essential hypertension. He found a progressive increase in systolic and diastolic pressure from CPITN score 0 to 4 $(p=0.0001$ and $p=0.05)$ [4]. These findings are comforting in that we found a significant relationship ( $\mathrm{p}<$ 0.001) between CPITN and hypertension after a simple logistic regression, despite the fact that there is a highly significant relationship between tooth loss $(p<0.001)$ and hypertension, as mentioned in many studies. After Engstrom et al. [13] who also found an association marginally significant $(\mathrm{p}=0.05)$, and especially Taguchi $e t$ al. [14], we can say that the potential frequency of periodontal pockets depends on the number of teeth present in the mouth. In addition, subjects with missing teeth may have more risk of periodontal disease compared to people with no tooth loss; which would result in endothelial dysfunction by oral infection, subsequent route for increased risk of hypertension.

\section{CONCLUSION}

Periodontal status plays an important role in the occurrence of hypertension. It is therefore necessary to have a 
more integrated approach taking into account the orodental factors in the treatment of hypertension.

\section{REFERENCES}

[1] Perk, J., De Backer, G., Gohlke, H., Graham, I., Reiner, Z., Verschuren, M., et al. (2012) European guidelines on cardiovascular disease prevention in clinical practice: The fifth joint task force of the European society of cardiology and other societies on cardiovascular disease prevention in clinical practice. European Journal Preventive Cardiology, 19, 585-667.

http://dx.doi.org/10.1177/2047487312450228

[2] Sowers, J.R., Epstein, M. and Frohlich, E.D. (2001) Diabetes, hypertension, and cardiovascular disease. Hypertension, 37, 1053-1059.

http://dx.doi.org/10.1161/01.HYP.37.4.1053

[3] Celermajer, D.S., Chow, C.K., Marijon, E., Anstey, N.M. and Woo, K.S. (2012) Cardiovascular disease in the developing world: Prevalences, patterns, and the potential of early disease detection. Journal of the American College of Cardiology, 60, 1207-1216. http://dx.doi.org/10.1016/j.jacc.2012.03.074

[4] Angeli, F., Verdecchia, P., Pellegrino, C., Giulia, P.R, Giacinto, P., Prosciutti, L., et al. (2003) Association between periodontal disease and left ventricle mass in essential hypertension. Hypertension, 41, 488-492. http://dx.doi.org/10.1161/01.HYP.0000056525.17476.D7

[5] Steyn, K., Sliwa, K., Hawken, S., Commerford, P., FCP, S.A., Onen, C., et al. (2005) For the INTERHEART investigators in Africa. Risk factors associated with myocardial infarction in Africa: The INTERHEART Africa study. Circulation, 112, 3554-3561. http://dx.doi.org/10.1161/CIRCULATIONAHA.105.5634 $\underline{52}$

[6] Kohal1, R.J, Lutter, G. and Dennison, D.K. (2001) Parodontite marginale et maladies cardio-vasculaires. Revue Mensuelle Suisse d'Odontostomatologie, 111, 451-454.

[7] Diallo, P.D., Benoist, H.M., Seck-Diallo, A., Diouf,
A.K.N.M. and Sembène, M. (2005) Les gingivites ulcéro nécrotique chez l'enfant sénégalais: Etude épidémiologique. Journal de Parodontologie et Implantologie Orale, 24, 169-176.

[8] Commission de Prévention et Santé Publique (2003) Foyers infectieux d'origine bucco-dentaire. Bulletin de l'Academie Nationale de Chirurgie Dentaire, 46, 159162.

[9] Leite, C.L., Redins, C.A., Vasquez, E.C. and Meyrelles, S.S. (2005) Experimental-induced periodontitis is exacerbated in spontaneously hypertensive rats. Clinical Experimental Hypertension, 27, 523-231. http://dx.doi.org/10.1081/CEH-200067688

[10] Martin, A. and Bercy, P. (2002) Revues des indices d'utilisation courante en en Parodontologie. Revue Belge de Medecine Dentaire, 3, 215-243.

[11] Tsakos, G., Sabbah, W., Hingorani, A.D., Netuveli, G., Donos, N., Watt, R.G., et al. (2010) Is periodontal inflammation associated with raised blood pressure? Evidence from a National US survey. Journal of Hyper- tension, 28, 2386-2393.

[12] Holmlund, A., Holm, G. and Lind, L. (2006) Severity of periodontal disease and number of remaining teeth are related to the prevalence of myocardial infarction and hypertension in a study based on 4254 subjects. Journal of Periodontology, 77, 1173-1178. http://dx.doi.org/10.1902/jop.2006.050233

[13] Engström, S., Gahnberg, L., Högberg, H. and Svärdsudd, K. (2007) Association between high blood pressure and deep periodontal pockets: A nested case-referent study. Upsala Journal of Medical Science, 112, 95-103. http://dx.doi.org/10.3109/2000-1967-099

[14] Taguchi, A., Sanada, M., Suei, Y., Ohtsuka, M., Lee, K, Tanimoto, K., et al. (2004) Tooth Loss is associated with an increased risk of hypertension in postmenopausal women. Hypertension, 43, 1297-1300. http://dx.doi.org/10.1161/01.HYP.0000128335.45571.ce 